\title{
Joshua D. Angrist and Jörn-Steffen Pischke (2009): Mostly Harmless Econometrics: An Empiricist's Companion
}

\author{
Princeton University Press, xiii +373 pp, Softcover, $€ 26.95$, \\ ISBN: 978-0691120355
}

\section{Christoph Hanck}

Published online: 24 October 2009

(C) The Author(s) 2009. This article is published with open access at Springerlink.com

Mostly Harmless Econometrics (MHE) covers well-known econometric methods such as linear regression and instrumental variables (Chaps. 3 and 4), but also more recent techniques like matching (Chap.3), panel data, differences-in-differences estimation (Chap. 5), regression discontinuity designs (Chap. 6) or quantile regression (Chap. 7). Many relevant empirical illustrations discuss prominent publications on questions from mostly labor economics. Examples include returns to schooling, the effect of class size on test scores or the effect of subsidized training on earnings.

This book is remarkable. Angrist and Pischke excel at spelling out under what conditions regression coefficients have a causal interpretation. They also devote careful attention to more practical issues such as constructing valid standard errors (Chap. 8). It is safe to predict that Angrist and Pischke's uniquely fresh writing style will appeal to a wider audience than that of the average econometrics textbook.

One is however tempted to feel that the publisher got a bit carried away with his marketing strategy for $M H E$. This is not an easy book, first impressions notwithstanding ("Mostly Harmless Econometrics shows how the basic tools of applied econometrics allow the data to speak."). Certainly, this book stands out as a more verbal way of discussing econometrics. But, this does not mean inherently complicated material is turned into something explained easily. Indeed, Angrist and Pischke resort to a rather conventional variable-laden Theorem-Proof style when verbal explanations are difficult-and that is more often than one would expect after reading the dustjacket ("The applied econometric methods emphasized in this book are easy to use.") So, it could be a matter of debate just how "unusual" and "quirky" (backcover) this book really is. Uninitiated readers are unlikely to fully understand the discussion without a solid foundation in, among others, probability (e.g., conditional expectation).

C. Hanck ( $\varangle)$

Rijksuniversiteit Groningen, Groningen, The Netherlands

e-mail: c.h.hanck@rug.nl 
The backcover reports enthusiastic reviews by experienced econometricians. This likely is no coincidence-I (without claiming to be one) also enjoyed MHE's fresh look on things already known (most of them). Only time spent with $M H E$ in the classroom will tell whether students who first hear about these topics will be similarly enthusiastic. At any rate, econometrics is a learning-by-doing science. Thus, in order to turn readers into good "empiricists", $M H E$ has to be complemented by exercises and real data sets. It is therefore great that many of the discussed results can be replicated using econ-www.mit. edu/faculty/angrist/data1/mhe.

The choice of topics is very selective. The authors mention in the book that the techniques covered are the most relevant ones in their major field of expertise, labor economics. The dustjacket paints a somewhat different picture: it claims "the core methods in today's econometric toolkit" are covered. All discussed techniques are important, but the casual reader might infer that there are few, if any, others. The rapid development of time series econometrics (to name but one example) over the last decades strongly suggests otherwise.

Similarly, the authors' view of what is and is not "unnecessarily fancy" is no doubt somewhat subjective. Many econometricians are probably willing to classify, e.g., quantile regression among the rather complicated techniques.

Summarizing, this reviewer believes that any reader stands to benefit from Mostly Harmless Econometrics as a complement to other econometric literature. The only question is whether it can serve as a substitute.

Open Access This article is distributed under the terms of the Creative Commons Attribution Noncommercial License which permits any noncommercial use, distribution, and reproduction in any medium, provided the original author(s) and source are credited. 